\title{
Interstitial cells of Cajal in the human fetal small bowel as shown by c-kit immunohistochemistry
}

\author{
T Wester, L Eriksson, Y Olsson, L Olsen
}

\begin{abstract}
Background-Interstitial cells of Cajal (ICCs) express the tyrosine kinase receptor c-kit, which is required for their development and spontaneous pacemaker activity in the bowel. From murine models it has been proposed that ICCs do not develop until after birth, but more recent findings indicate that c-kit is expressed early in the embryonic period. The temporal development of ICCs in the human gut remains unknown.
\end{abstract}

Aim-To investigate ICCs in the human fetal small bowel using c-kit immunohistochemistry.

Subjects-Small bowel specimens were obtained at post mortem examination of 16 fetuses and nine neonates, eight of whom were premature, born at gestational ages of 13 to 41 weeks, without gastrointestinal disorders.

Methods-Immunohistochemical analysis was performed on material fixed in formalin and embedded in paraffin. The specimens were exposed to antibodies raised against c-kit (an ICC marker) and neurone specific enolase (a general neuronal marker). The ABC complex method was used to visualise binding of antibodies to the corresponding antigens.

Results-c-kit immunoreactive cells were visualised from 13 weeks of gestation. The immunoreactivity was mainly localised in association with the myenteric plexus. From about 17-18 weeks of gestation, the ICCs formed a layer along the myenteric plexus, whereas this layer appeared to be disrupted at 13-16 weeks of gestation. Conclusions-ICCs are c-kit immunoreactive at least from a gestational age of 13 weeks in the human fetal small intestine. From 17-18 weeks of gestation until birth, they form a continuous layer around the myenteric ganglia.

(Gut 1999;44:65-71)

Keywords: interstitial cells of Cajal; c-kit; myenteric plexus; human; fetal; development

Although it is now more than a century since the interstitial cells of Cajal (ICCs) first attracted the interest of scientists, ${ }^{12}$ many questions about these cells remain unanswered, particularly with respect to their function. Furthermore, the ontogeny and development of ICCs, especially in the human gastrointestinal tract, require further investigation, and these questions were addressed in the present study.
In the human small bowel, the ICCs are localised at the level of the myenteric plexus between the longitudinal and circular muscle layers, in the deep muscular plexus in the innermost part of the circular muscle layer, and within the circular muscle layer itself. ${ }^{3-5}$ They are considered to be generators of spontaneous pacemaker activity in the smooth muscle layers of the gut. ${ }^{6-9}$ Furthermore, it has been suggested that they may be involved in neurotransmission. ${ }^{9}$ A cytokine, steel factor, ${ }^{10}$ also termed stem cell factor $(\mathrm{SCF})^{11}$ or mast cell growth factor (MGF), ${ }^{12}$ has been identified as the c-kit ligand. Huizinga et $a l^{13}$ showed that ICCs associated with the myenteric plexus express c-kit, which is a proto-oncogene encoding a cell surface receptor tyrosine kinase. ${ }^{14}$ Mice with mutations in the white spotting (W) locus, resulting in kit gene mutations, lack ICCs associated with the myenteric plexus as well as intestinal pacemaker activity.

In conclusion, ICCs appear to have a key role in the normal function of the intestine, and alterations in these cells may well be involved in various intestinal disorders. For instance, in Hirschsprung's disease there are considerably fewer ICCs in the aganglionic segment than in the ganglionic bowel. ${ }^{15} 16$ The absence or reduction of c-kit immunoreactive cells in association with the myenteric plexus has also been observed in infantile hypertrophic pyloric stenosis. ${ }^{17}$ Recently, Isozaki et $a l^{18}$ reported two cases of myopathic chronic intestinal pseudoobstruction with decreased numbers of c-kit immunoreactive cells associated with the myenteric plexus.

To our knowledge, the temporal development of ICCs in the human gastrointestinal tract has not been systematically investigated previously. The purpose of this study was therefore to map c-kit immunoreactivity as an ICC marker in the small intestine from human fetuses at different gestational ages. Neurone specific enolase (NSE) immunohistochemistry was used as a marker of the neuronal component, which has already been well defined in the human fetal small bowel. ${ }^{19}$ Information on the ICCs may contribute to our understanding of the development of small bowel motility in premature babies in whom this motility appears immature in the fasting state, ${ }^{20} 21$ although it has been reported that premature babies respond appropriately to feeding. ${ }^{22}$ Furthermore, knowledge of ICC development may help to clarify the aetiology

Abbreviations used in this paper: ICC, interstitial cells of Cajal; SCF, stem cell factor; MGF, mast cell growth factor; NSE, neurone specific enolase; PBS phosphate buffered saline. 
Table 1 Data on the subjects

\begin{tabular}{rlll}
\hline Case & $\begin{array}{l}\text { Gestational age } \\
\text { (weeks) }\end{array}$ & $\begin{array}{l}\text { Age at death } \\
\text { (days)/death in utero } \\
\text { (iu) }\end{array}$ & \\
\hline 1 & 13 & iu & Diagnosis \\
2 & 15 & iu & Anencephaly \\
3 & 15 & iu & Anencephaly \\
4 & 16 & iu & Amnion band syndrome \\
5 & 17 & iu & Anencephaly \\
6 & 17 & iu & Fragile X syndrome \\
7 & 18 & iu & Unknown \\
8 & 18 & iu & Ablatio placentae, chorioamnionitis \\
9 & 20 & iu & Dysplastic kidneys \\
10 & 20 & iu & Down's syndrome \\
11 & 21 & 1 & Unknown \\
12 & 21 & 1 & Cerebral haemorrhage \\
& & & Pulmonary haemorrhage, cerebral \\
13 & 23 & 15 & haemorrhage \\
& & & Aortic thrombosis, renal infarction, \\
14 & 25 & 1 & cerebral haemorrhage \\
15 & 25 & 2 & RDS, cerebral haemorrhage \\
16 & 25 & 14 & Septicaemia, pulmonary haemorrhage \\
17 & 26 & 17 & Pneumonia, septicaemia \\
18 & 31 & iu & Septicaemia, cerebral haemorrhage \\
19 & 31 & iu & Unknown \\
20 & 34 & iu & Meckel-Gruber syndrome \\
21 & 35 & 2 & Unknown \\
22 & 36 & iu & Unknown \\
23 & 36 & 4 & Polycystic kidney disease \\
24 & 41 & & Asphyxia in utero \\
25 & 41 & & Unknown \\
& & Pulmonary hypertension, bilateral \\
& & pneumothorax \\
\hline & & & iu \\
\hline
\end{tabular}

${ }^{\star}$ Unknown means that the cause of death was not established at autopsy. RDS, respiratory distress syndrome.

and pathophysiology of disorders characterised by a deficiency of ICCs.

\section{Methods}

Specimens from the mid part of the small bowel were collected for diagnostic purposes at routine post mortem examination of 16 fetuses and nine newborns, eight of whom were born prematurely. The gestational age ranged from 13 to 41 weeks (table 1 ). The liveborn babies died between the first and 17th day of life. Seven of these were born at 21-27 weeks of gestation. Post mortem examination was performed one to six days after death. Mild maceration was found in three of the fetuses who died in utero; stillbirths with severe maceration were not included. Furthermore, fetuses and infants displaying grossly pathological conditions of the gastrointestinal tract were not included. The morphology of the bowel wall was normal in all cases at routine histopathological examination of haematoxylin and eosin stained sections, although the mucosa showed autolytic alterations in several subjects. Specimens were also obtained from the rectum in five cases at 13, 19, 19, 23, and 31 weeks of gestation. As control tissue, specimens from the distal ileum were collected at the time of ileocaecal resection in three cases. The resections were performed because of colonic cancer, villous adenoma, and perforated appendicitis, and the patients were 63,75 , and 78 years old.
The study was approved by the ethics committee of the Faculty of Medicine of Uppsala University.

\section{TISSUE PREPARATION}

The specimens were fixed in $10 \%$ formalin and embedded in paraffin. Sections $5 \mu \mathrm{m}$ thick were cut, placed on poly-L-lysine coated slides, and incubated at $37^{\circ} \mathrm{C}$ overnight. All sections were deparaffinised in xylene and hydrated.

\section{IMMUNOHISTOCHEMISTRY}

Antigen retrieval by microwave oven heating was performed for both antibodies. The sections were boiled $(750 \mathrm{~W})$ in citric acid buffer (10 $\mathrm{mM}, \mathrm{pH}$ 6.0) for five (NSE) or ten (c-kit) minutes. The sections were allowed to cool to room temperature in the buffer and then rinsed in phosphate buffered saline (PBS, $\mathrm{pH}$ 7.4). The endogenous peroxidase activity was blocked in $2 \%$ hydrogen peroxide in distilled water for five minutes and the sections were then rinsed in PBS. Thereafter they were incubated with normal swine serum (Dako, Glostrup, Denmark; dilution 1:5) for c-kit or normal goat serum (Dako; dilution 1:5) for NSE in PBS for 20 minutes at room temperature. Incubation with the primary antibody took place overnight at $4^{\circ} \mathrm{C}$ (c-kit) or for one hour at room temperature (NSE). Table 2 provides a further description of the primary antibodies. After being rinsed in PBS, the slides were incubated with a biotinylated secondary antibody, goat antimouse (Dako, product number E0433; dilution 1:200) for NSE or swine anti-rabbit (Dako, product number E0353; dilution 1:300) for c-kit, for 30 minutes at room temperature. The sections were then incubated in Vectastain elite ABC kit (Vector Laboratories, Burlingame, California, USA) for 30 minutes and developed in 3,3'-diaminobenzidine tetrahydrochloride (Sigma, London, UK) for about six minutes. Counterstaining with haematoxylin was performed. Finally, the sections were dehydrated, cleared in xylene and mounted in Pertex (Histolab, Göteborg, Sweden).

Immunoreactivity was absent in negative controls in which the primary antibody was omitted. For c-kit, the immunostaining was also abolished by a blocking peptide $(1.0 \mu \mathrm{g} / \mathrm{ml}$; \#sc-168p; Santa Cruz Biotechnology, Santa Cruz, California, USA), incubated with c-kit antibody $(0.01 \mu \mathrm{g} / \mathrm{ml})$ for two hours at room temperature, before the specific immunohistochemical procedure, according to instructions provided by the suppliers.

The slides were analysed by light microscopy.

Table 2 Survey of the antibodies used

\begin{tabular}{lllll}
\hline Antibody & Clone/product no & Characteristics & Source & Dilution \\
\hline c-kit & \# sc-168 & $\begin{array}{l}\text { Polyclonal, rabbit, anti-human, raised } \\
\text { against peptide corresponding to } \\
\text { amino acids 958-976 within carboxy } \\
\text { terminal domain of human c-kit }\end{array}$ & Santa Cruz Biotechnology & $0.1 \mu \mathrm{g} / \mathrm{ml}$ \\
NSE & BBS/NC/VI-H14 & Monoclonal, mouse, anti-human & Dako & $1: 100$ \\
\hline
\end{tabular}

NSE, neurone specific enolase. 

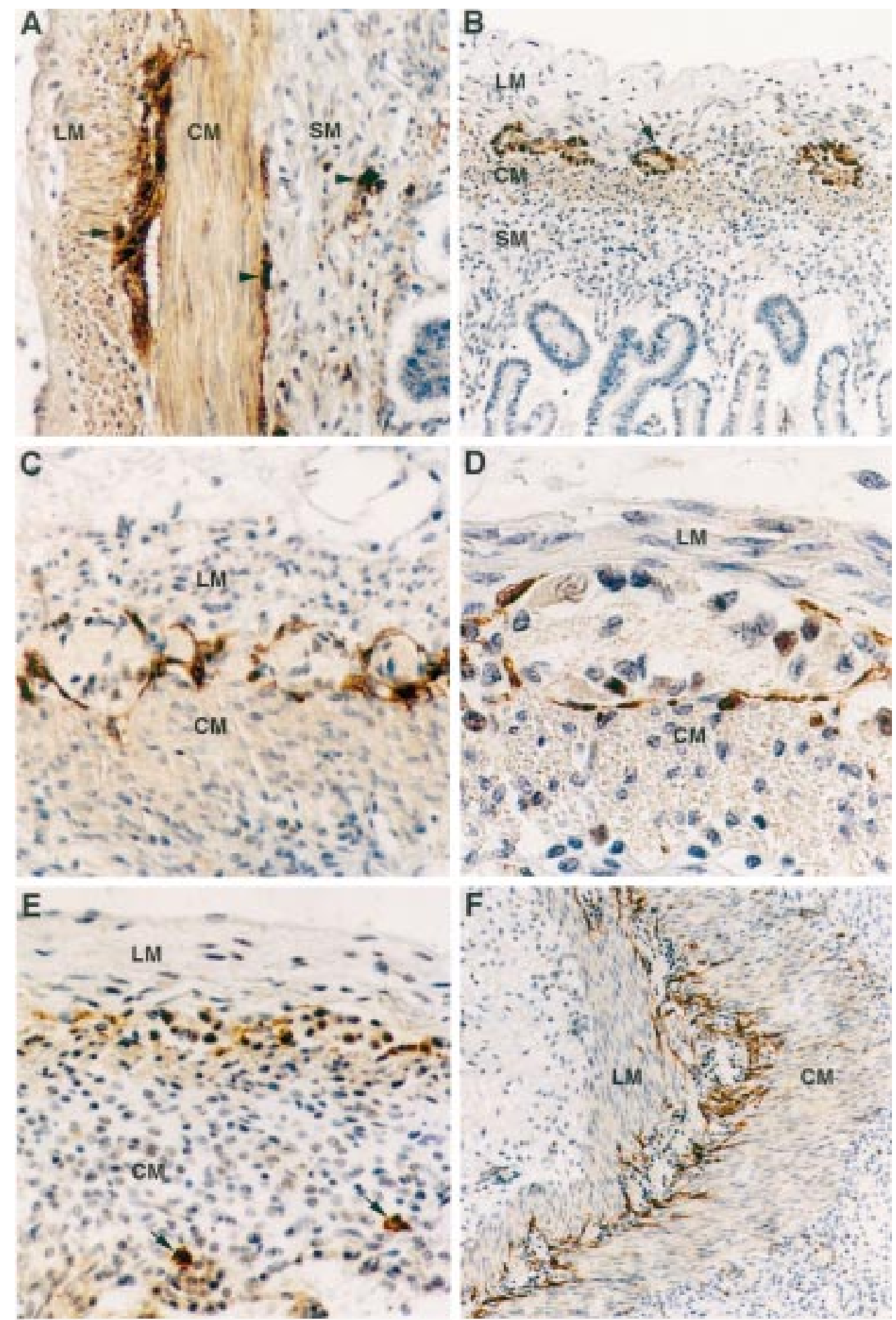

Figure 1 (A) NSE immunohistochemistry showing immunoreactive ganglion cells in the myenteric plexus (arrow) and in the inner and outer submucous plexuses (arrowheads) of the small bowel in an infant born at 26 weeks of gestation who died at the age of 17 days. Nerve fibres associated with the ganglia and in the circular muscle layer are also stained. Original magnification $\times 66$. (B) NSE immunohistochemistry of the small bowel at 13 weeks of gestation displays the myenteric plexus (arrow), whereas no immunoreactive ganglion cells were present in the submucosa. Original magnification $\times 40$. (C) From 17-18 weeks of gestation, the ICCs form a continuous layer along the myenteric plexus of the small bowel. This is illustrated in a case at 20 weeks of gestation using c-kit immunohistochemistry. Original magnification $\times 80$. (D) c-kit immunoreactive cells are elongated in shape and have an ovoid nucleus as in this case at 20 weeks of gestation. The cell processes do not seem to penetrate into the ganglia. Original magnification $\times 200$. (E) From 13 to 16 weeks of gestation, the layer of c-kit immunoreactive ICCs associated with the myenteric plexus of the small bowel appears to be disrupted. In the submucosa, isolated round c-kit immunoreactive cells, interpreted as mast cells, are seen (arrows). In this case the submucous plexus had not yet developed at 13 weeks of gestation, as shown in (B). Original magnification $\times 80$. (F) From 17 weeks of gestation, the processes of the ICCs are often seen to penetrate into the circular muscle layer, whereas isolated ICCs in this layer are only rarely observed. Original magnification $\times 50$. Abbreviations: LM, longitudinal muscle layer; CM, circular muscle layer; SM, submucosa. 


\section{Results}

NSE IMMUNOHISTOCHEMISTRY

NSE immunohistochemistry clearly showed the myenteric and submucous plexuses. NSE immunoreactivity was observed in the nerve cell bodies and also in nerve fibres in the intermuscular space and submucosa (fig 1A). The myenteric plexus was established in all cases. On the other hand, the submucous plexus was absent in the earliest case (13 weeks of gestation, fig 1B). In several of the early subjects submucous ganglia were identifiable, but it was difficult to distinguish an inner and outer plexus and most of the immunoreactive cells were observed close to the circular muscle layer. In the older subjects, separate inner and outer plexuses were established and clearly visualised (fig 1A). We did not observe any NSE immunoreactive cells with morphological features characteristic of ICCs.

C-KIT IMMUNOHISTOCHEMISTRY

c-kit immunoreactivity was observed in all but two cases, at gestational ages of 31 and 35 weeks. NSE immunoreactivity was normal in these cases. There was no obvious reason for the negative results, but post mortem changes may have contributed as these fetuses were mildly macerated. Both fetuses died in utero and the cause of death could not be established at post mortem examination. The c-kit immunoreactive cells were situated in the intermuscular space, and most of the c-kit positive cells were thin and elongated and had an ovoid nucleus, surrounding the myenteric ganglia and nerve fascicles (figs $1 \mathrm{C}$ and D). In subjects older than about 17-18 weeks of gestation, a continuous layer of c-kit immunoreactive cells was usually observed around the myenteric plexus (fig 1C). On the other hand, at a gestational age of 13-16 weeks this layer of cells appeared to be disrupted, and immunoreactive cells with a round nucleus and short processes were found. Furthermore, in these cases the immunoreactivity was weak and few immunopositive cells were seen (fig $1 \mathrm{E}$ ). In almost all cases, round immunoreactive cells were observed in the submucosa without any association with the submucous ganglia; these were interpreted as mast cells, which are known to be c-kit immunoreactive (fig $1 \mathrm{E}$ ). ${ }^{23}$ Although the c-kit positive cells often extended into the smooth muscle layers (fig $1 \mathrm{~F}$ ), isolated immunopositive cells were rarely seen in the muscle layers. No differences between the liveborn neonates and the fetuses who died in utero could be distinguished. In the rectum specimens, similar findings were encountered. However, at 13 weeks of gestation no c-kit immunoreactivity could be observed around the myenteric plexus (fig 2A). At 19 weeks of gestation c-kit immunoreactive cells were rare in one of the cases, whereas in the second case, the myenteric ganglia were outlined by c-kit immunoreactive ICCs (fig 2B). The latter pattern was also observed at 23 and 31 weeks of gestation. In the adult small intestine, large numbers of ICCs were found around the myenteric ganglia. The number of ICCs in the circular muscle layer was larger than in the fetal cases (fig 2C).

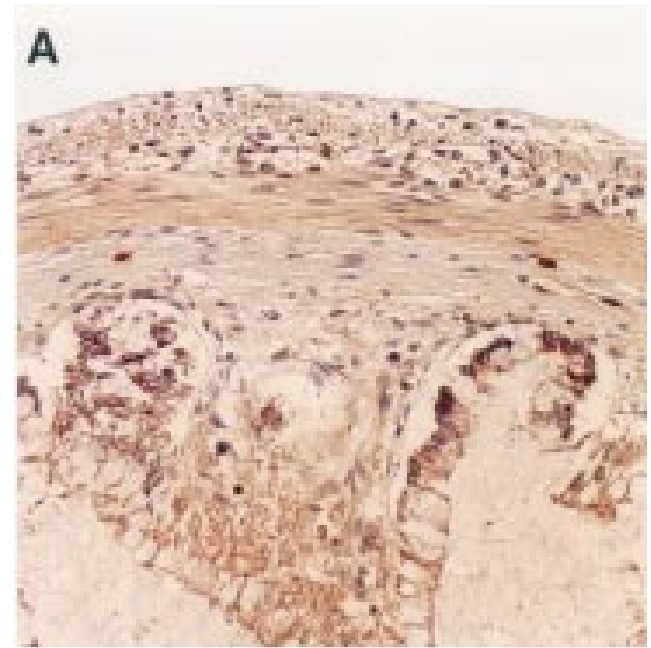

B

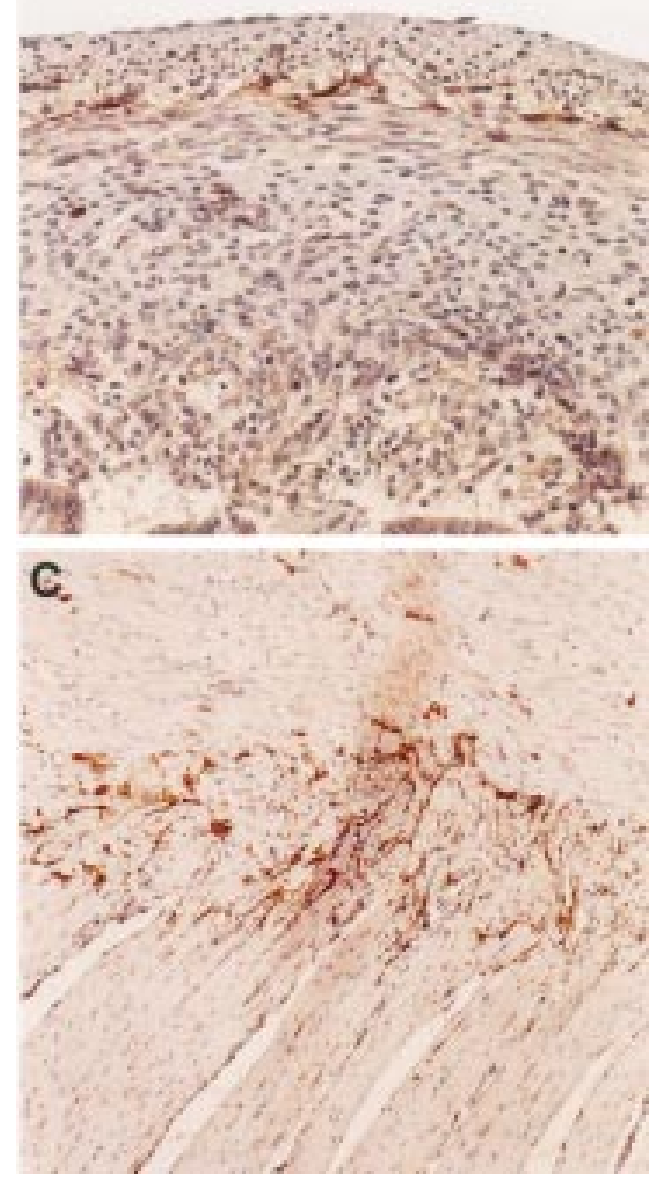

Figure 2 (A) At 13 weeks of gestation no c-kit immunoreactivity can be seen in association with the myenteric plexus of the rectum. Original magnification $\times$ 50. (B) A layer of c-kit immunoreactive ICCs is seen around the myenteric plexus of the rectum at 19 weeks of gestation. Original magnification $\times 50$. (C) In the adult small bowel, c-kit immunoreactive ICCs surround the myenteric ganglia. ICCs are also frequently found in the circular muscle layer. Original magnification $\times 25$.

\section{Discussion}

The morphology and distribution of ICCs have previously been difficult to study, as standard staining procedures for conventional light microscopy do not disclose this cell type. 
Consequently, electron microscopy has been the method of choice for investigations of the distribution of ICCs, and several ultrastructural studies have in fact been performed on human small bowel using this technique..$^{3-5}$ Ultrastructurally, ICCs associated with the myenteric plexus are arranged in bundles surrounding the ganglia and nerve fascicles, with which they are always in close contact. The processes of ICCs are long and usually do not branch. Characteristically, the ICC processes contain a well developed smooth endoplasmic reticulum and a dense meshwork of intermediate filaments. The perinuclear cytoplasm also contains many intermediate filaments, but less abundant smooth endoplasmic reticulum. The chromatin pattern of the ICC nucleus is similar to that observed in smooth muscle cells. However, in contrast with smooth muscle cells, ICCs do not contain myosin filaments. ${ }^{4}$

It has been shown in mouse, ${ }^{24}$ guinea pig, ${ }^{25}$ and human bowe ${ }^{15}$ that the morphology of the c-kit immunoreactive cells associated with the myenteric plexus correlates with the ultrastructural descriptions of ICCs. ICCs are intercalated between varicose nerve endings and smooth muscle cells. Two types of varicosities have been identified in the nerve endings. The first may be cholinergic, whereas the second, which is more commonly encountered in association with the deep muscular plexus ICCs than in those associated with the myenteric plexus, is morphologically similar to varicosities seen in inhibitory non-adrenergic non-cholinergic neurones. ${ }^{9}$ These findings indicate that ICCs may play a role in inhibitory neurotransmission, which was further investigated by Publicover et $a l,{ }^{26}$ who proposed that these cells may amplify the inhibitory nitric oxide signalling in canine colon. The demonstration of nitric oxide synthase, the endothelial isoform, in ICCs indicates that this cell type is able to synthesise nitric oxide. ${ }^{27}$

Maeda et $a l^{23}$ found that c-kit plays a major role in the development of the pacemaker system in the gut and proposed that ICCs were involved. Administration of an antagonistic anti-c-kit antibody to newborn mice resulted in abnormal intestinal motility. ${ }^{23}$ Several other investigators have presented results supporting the role of ICCs in generating spontaneous pacemaker activity. For instance, removal of the submucosa from the circular muscle layer, disrupting the submucosa-circular muscle interface which is the location of one class of ICCs, was found to abolish slow waves in the canine colonic circular muscle. ${ }^{7}$ Methylene blue perfusion combined with illumination of intestinal smooth muscle preparations resulted in selective damage to the ICCs and loss of slow wave activity. ${ }^{6}$ Furthermore, exposure of ICCs to rhodamine 123, which is a fluorescent dye taken up by ICCs and enteric neurones but not by smooth muscle cells, altered the electrical rhythmicity of canine colonic circular muscle preparations. ${ }^{28}$

The embryonic origin of ICCs has been debated. Recently, however, Lecoin et $a l^{29}$ investigated the origin of the c-kit positive cells in avian bowel. Quail neural crest was grafted to chicken embryos at embryonic day 2 . The experiment showed that all enteric neurones and glial cells were of quail origin, whereas all c-kit immunoreactive cells originated from the chick. The authors concluded that the c-kit positive ICCs have a mesenchymal origin.

In an ultrastructural study of murine small bowel, Faussone-Pellegrini ${ }^{30}$ reported that ICCs were not detected in term fetuses, but appeared during the first two weeks of life. On the other hand, Torihashi et $a l^{4}$ detected c-kit immunoreactivity in the murine small intestine at embryonic day 12 (E12). At this stage the c-kit positive cells were found at the outer surface of the bowel wall just beneath the serosal layer. These cells could not be characterised as either ICCs or smooth muscle cells. The ICC network associated with the myenteric plexus developed between days E15 and E18. The authors suggested that a population of cells that were c-kit positive at day E12 differentiated into smooth muscle cells, losing the c-kit immunoreactivity, whereas others continued to express c-kit immunoreactivity and differentiated into ICCs associated with the myenteric plexus. The c-kit immunoreactivity did not co-localise with the neuronal marker c-ret, indicating that ICCs are not of neuronal origin. The ICCs associated with the deep muscular plexus developed after birth. The development of ICCs in the human fetal bowel remains unclear, which was the reason for the present study. Matsuda et $a l^{11}$ investigated c-kit expression in normal adult and fetal human tissue and found c-kit immunoreactivity in enteric nervous plexuses in adult tissue, but not in fetal tissue. On the other hand, they observed c-kit immunoreactive cells in the brain in both tissues. Vanderwinden et $a l^{15}$ mentioned that c-kit immunoreactive ICCs appeared in the human foregut at gestational week 14 and in the hindgut at 23 weeks of gestation but without further description. Horie et $a l^{\beta 2}$ found c-kit immunoreactivity in the smooth muscle layers of human fetal oesophagus, small bowel, and colon at 18 and 20 weeks of gestation.

We observed c-kit immunoreactivity in elongated cells with an ovoid nucleus around the myenteric ganglia. The typical localisation and morphology of the c-kit immunoreactive cells visualised in our study indicate that they are ICCs. It has previously been shown that ICCs associated with the myenteric plexus express the c-kit tyrosine kinase receptor. ${ }^{13}$ Prosser et $a l^{33}$ reported that some ICCs associated with the myenteric plexus were NSE immunoreactive in the rat intestine. However, these findings were not corroborated in our study, as we did not observe NSE immunoreactive cells with morphological features or localisations characteristic of ICCs. Our findings indicate that ICCs express c-kit at least as early as at 13 weeks of gestation in the human fetal small bowel, although the morphology and distribution of the ICCs at this stage suggest that they are still immature. At a gestational age of 13-16 weeks, few dispersed ICCs were observed in the intermuscular space and some of the individual cells had short processes and a round 
nucleus. In the rectum specimens, no immunoreactivity was observed at this gestational age. From 17-18 weeks of gestation a continuous layer of c-kit immunoreactive ICCs was observed around the myenteric ganglia and nerve fascicles in the small bowel, and we detected no further alterations from this gestational age until full term. From about 19 weeks of gestation, c-kit immunoreactive ICCs had developed in association with the rectal myenteric ganglia. We did not observe any c-kit immunoreactive cells in the region of the deep muscular plexus in the fetal cases, although ICCs have been observed at this site in ultrastructural studies of adult human small bowel. ${ }^{5}$ One explanation for the absence of c-kit immunoreactive ICCs in the deep muscular plexus in the fetal cases may be that ICCs of this type develop after birth, as in the murine small bowel. ${ }^{24}$ However, Isozaki et al ${ }^{18}$ only found a few c-kit immunoreactive cells in the deep muscular plexus in human adults, which may indicate that it is mainly the ICCs associated with the myenteric plexus that are c-kit positive in the human small bowel. We found numerous c-kit positive ICCs in the circular muscle layer in the adult cases, but it was difficult to distinguish a separate deep muscular plexus.

In the murine small bowel, it has been shown that the onset of electrical rhythmicity correlates with the development of ICCs. At E16 and E17 spontaneous electrical activity was absent, whereas slow waves could be recorded at E19 when the ICCs and the longitudinal muscle layers had differentiated into two distinct entities. ${ }^{24}$ In mice, the slow wave frequency has been shown to correlate with variations in the intraluminal pressure, which results in propulsive peristalsis as shown by radiological methods. ${ }^{34} \mathrm{McLain}^{35}$ investigated human fetal gastrointestinal motility by amniography and could not show any emptying of contrast from the stomach before about 30 weeks of gestation. However, from 30 weeks of gestation, the rate of propagation of contrast increased with increasing gestational age. Bisset et $a l^{20}$ studied small intestinal pressures in preterm infants from 28 weeks of gestation until term. Before 31 weeks of gestation a disorganised activity pattern with low amplitude was found. Between 31 and 34 weeks of gestation, clustered phasic activity appeared, and from 34 to 37 weeks of gestation prolonged phasic activity was observed propagating in aboral direction. At term a well defined fasting motor activity with migrating motor complexes was discernible. However, Berseth ${ }^{22}$ showed that preterm infants respond appropriately to feeding administered as infusion, by developing persistent activity. The responses to feeding among prematures did not differ from that of term infants. The slow wave frequency which has been associated with ICC function increases with gestational age from 10.5 cycles per minute at 28 weeks of gestation to 12.5 cycles per minute at term. ${ }^{20}$

It is difficult to investigate normal human fetal development. Ethical aspects of collecting and using material must be considered. Fur- thermore, the great variation seen in human material as opposed to animal models may make interpretation difficult. Our material comprised specimens obtained at autopsy after induced termination or spontaneous abortion and specimens from liveborn babies who died within the first weeks of life. A wide range of malformations and disorders were encountered, but we could not distinguish any abnormalities in the expression of NSE or c-kit immunoreactivity which could be related to these conditions. However, the absence of c-kit immunoreactivity in two of our cases may well be explained by post mortem changes or events occurring before death. It has previously been pointed out that events before death, such as hypoxaemia, may influence the staining properties of enteric ganglia in studies using silver impregnation $^{36}$ or NADPH diaphorase histochemistry. ${ }^{37}$ The effects of autolysis are always a concern when autopsy material is used, but it has been reported that many antigens are surprisingly resistant to post mortem changes. ${ }^{38}$

In conclusion, ICCs associated with the myenteric plexus in the human fetal small bowel express the c-kit tyrosine kinase receptor at least from 13 weeks of gestation. From about 17-18 weeks of gestation the c-kit immunoreactive ICCs form a layer of cells surrounding the myenteric ganglia and nerve fascicles. However, at 13-16 weeks this cell layer appeared to be disrupted, which may indicate that ICCs are still in a phase of development at that stage.

This work was supported by the HRH Crown Princess Louisa's Association for Child Medical Care and the Ollie and Elof Ericsson Foundation for Scientific Research. We are also grateful to Gunilla Tibbling and Frank Bittkowski for their photographic assistance and to Bengt Sandstedt who contributed specimens.
and

1 Cajal SR. Sur les ganglions nerveux de l'intestin. $C R$ Seances Soc Biol Fil 1893;45:217-23.

2 Cajal SR. Histologie du système nerveux de l'homme et des vertébrés. Paris: Maloine, 1911;2:891-942.

3 Rumessen JJ, Mikkelsen B, Qvortrup, et al. Ultrastructure of interstitial cells of Cajal in circular muscle of human small intertine. Gastroenterology 1993;104:343-50.

4 Rumessen JJ, Thuneberg L. Interstitial cells of Cajal in human small intestine. Ultrastructural identification and organisation between the main smooth muscle layers. Gasorganisation between the main smo
troenterology 1991;100:1417-31.

5 Rumessen JJ, Mikkelsen HB, Thuneberg. Ultrastructure of interstitial cells of Cajal associated with deep muscular plexus of human small intestine. Gastroenterology 1992;102: 56-68.

6 Liu LWC, Thuneberg L, Huizinga JD. Selective lesioning of interstitial cells of Cajal by methylene blue and light leads to loss of slow waves. Am f Physiol 1994;266:G485-96.

7 Durdle NG, Kingma YJ, Bowes KL, et al. Origin of slow waves in the canine colon. Gastroenterology 1983;84:375-82.

8 Liu LWC, Huizinga JD. Electrical coupling of circular muscle to longitudinal muscle and interstitial cells of Cajal in canine colon. $\mathcal{F}$ Physiol (Lond) 1993;470:445-61.

9 Thuneberg L. Interstitial cells of Cajal: intestinal pacemaker cells? Adv Anat Embryol Cell Biol 1982;71:1-130.

10 Flanagan JG, Leder P. The kit ligand: a cell surface molecule altered in steel mutant fibroblasts. Cell 1990;63:185-94.

11 Zsebo KM, Wypych J, McNiece IK, et al. Identification, purification, and biological characterisation of haematopoietic stem cell factor from Buffalo rat liver-conditioned medium. Cell 1990;63:195-201.

12 Williams DE, Eisenmann J, Baird A, et al. Identification of a ligand for the c-kit proto-oncogene. Cell 1990;63:167-74.

13 Huizinga JD, Thuneberg L, Klüppel M, et al. W/kit gene required for interstitial cells of Cajal and for intestinal pacemaker activity. Nature 1995;373:347-9.

14 Yarden Y, Kuang W-J, Yang-Feng T, et al. Human protooncogene c-kit: a new cell surface receptor tyrosine kinase for oncogene c-kit: a new cell surface receptor tyrosine

15 Vanderwinden J-M, Rumessen JJ, Liu H, et al. Interstitial cells of Cajal in human colon and in Hirschsprung's disease. Gastroenterology 1996;111:901-10. 
16 Yamataka A, Kato Y, Tibboel D, et al. A lack of intestinal pacemaker (c-kit) in aganglionic bowel of patients with
Hirschsprung's disease. F Pediatr Surg 1995;30:441-4.

17 Vanderwinden J-M, Liu H, De Laet M-H, et al. Study of the interstitial cells of Cajal in infantile hypertrophic pyloric stenosis. Gastroenterology 1996;111:279-88.

18 Isozaki K, Hirota S, Miyagawa J-I, et al. Deficiency of c-kit+ cells in patients with a myopathic form of chronic idiopathic intestinal pseudo-obstruction. Am F Gastroenterol 1997;92:332-4.

19 Fekete E, Benedeczky I, Timmermans J-P, et al. Sequential pattern of nerve-muscle contacts in the small intestine of developing human fetus. An ultrastructural and immunohistochemical study. Histol Histopathol 1996;11:845-50.

20 Bisset WM, Watt JB, Rivers RP, et al. Ontogeny of fasting small intestinal motor activity in the human infant. Gut 1988;29:483-8.

21 Berseth CL. Gestational evolution of small intestine motility in preterm and term infants. F Pediatr 1989;115:646-51.

22 Berseth CL. Neonatal small intestinal motility: motor responses to feeding in term and preterm infants. $\mathcal{F}$ Pediatr 1990;117:777-82.

23 Maeda H, Yamagata A, Nishikawa S, et al. Requirement of c-kit for development of intestinal pacemaker system. Development 1992;116:369-75.

24 Torihashi S, Ward SM, Sanders KM. Development of c-kitpositive cells and the onset of electrical rhythmicity in murine small intestine. Gastroenterology 1997;112:144-55

25 Burns AJ, Herbert TM, Ward SM, et al. Interstitial cells of Cajal in the guinea-pig gastrointestinal tract as revealed by c-kit immunohistochemistry. Cell Tissue Res 1997;290:1120.

26 Publicover NG, Hammond EM, Sanders KM. Amplification of nitric oxide signaling by interstitial cells isolated from canine colon. Proc Natl Acad Sci USA 1993;90:2087-91.

27 Xue C, Pollock J, Schmidt HHHW, et al. Expression of nitric oxide synthase by interstitial cells of the canine proximal colon. F Auton Nerv Syst 1994;49:1-14.
28 Ward SM, Burke EP, Sanders KM. Use of Rhodamine 123 to label and lesion interstitial cells of Cajal in canine colonic circular muscle. Anat Embryol (Berl) 1990;182: 215-24.

29 Lecoin L, Gabella G, Le Douarin N. Origin of the c-kit positive interstitial cells in the avian bowel. Development 1996;122:725-33

30 Faussone-Pellegrini MS. Cytodifferentiation of the interstitial cells of Cajal related to the myenteric plexus of mouse intestinal muscle coat. A EM study from foetal to adult life. Anat Embryol (Berl) 1985;171:163-9.

31 Matsuda R, Takahashi T, Nakamura S, et al. Expression of the c-kit protein in human solid tumours and in corresponding fetal and adult normal tissues. Am f Pathol 1993;142:339-46.

32 Horie K, Fujita J, Takakura K, et al. The expression of c-kit protein in human adult and fetal tissues. Hum Reprod 1993; 8:1955-62.

33 Prosser CL, Holzwarth MA, Barr L. Immunohistochemistry of the interstitial cells of Cajal in the rat intestine. 7 Auton Nerv Syst 1989;27:17-25.

34 Der-Silaphet T, Malysz J, Hagel S, et al. Interstitial cells of Cajal direct normal propulsive contractile activity in the mouse small intestine. Gastroenterology 1998,114:724-36.

35 McLain CR. Amniography studies of the gastrointestinal motility of the human fetus. Am F Obstet Gynecol 1963;86: 1079-87.

36 Smith B. Changes seen in the myenteric plexus not due to primary disease. In: Smith B, ed. The neuropathology of the alimentary tract. London: Edward Arnold, 1972:17-20.

37 Wester T, O'Briain DS, Puri P. NADPH diaphorase containing nerve fibers and neurons in the myenteric plexus are resistant to postmortem changes. Arch Pathol Lab Med 1998;122:461-6.

38 Knuden LM, Pallesen G. The preservation and loss of various nonhaematopoietic antigens in human postmortem tissues as demonstrated by monoclonal antibody immunohistological staining. Histopathology 1986;10:1007-14. 